\title{
Cervical, Thoracic, and Lumbosacral Spinal Cord Ependymal Tumor
}

National Cancer Institute

\section{Source}

National Cancer Institute. Cervical, Thoracic, and Lumbosacral Spinal Cord Ependymal

Tumor. NCl Thesaurus. Code C131609.

An ependymal tumor affecting the spinal cord in the cervical, thoracic, and lumbosacral regions. 